\title{
Semi-active Fuzzy Control for Machine Tool Vibration
}

\author{
Chunmei $\mathrm{Li}^{1,2, \mathrm{a}}$ and Weina Liü, 2, a, b* \\ ${ }^{1}$ College of Mechanical and Electric Engineering, Changchun University of Science and Technology, \\ 130012, China \\ ${ }^{2}$ College of Mechanical and Electric Engineering, College of Optical and Electronical Information \\ Changchun University of Science and Technology, 130012, China \\ a450734640@qq.com, bwhliu77@163.com
}

Keywords: Vibration control, Intelligent material, Magneto-rheological Fluid, Fuzzy control.

\begin{abstract}
Intelligent material is widely used in the semi-active vibration control systems due to its the advantages as simple control, responding quickly, easy control of characteristic parameters, low power consumption and strong robustness. In this paper, the damping device for machine tool based on intelligent materials so called magneto-rheological fluid was developed to reduce vibration in the rectangle parts milling. The theory showed that the best damping effect is getting about optimal damping ratio 0.26 . Thus, a fuzzy control system with magneto-rheological fluid for the damping device for machine tool was developed. The test results showed that under cutting conditions without the magneto-rheological damper the fuzzy control system can effectively reduce the amplitude and suppress the vibration of the machine tool.
\end{abstract}

\section{Introduction}

With the diversification of modern production scale, continuous development of science and technology as well as advanced manufacturing technology requirements, for precision and ultra precision machine tools, high machining precision and ultra smooth machining quality must be strictly guaranteed, requiring machine work to smooth, with minimal vibration., Therefore, the vibration reduction of machine tools is the key technology to guarantee the precision and ultra precision machining. The harm of machine tool vibration is obvious, reduce parts processing precision and quality, cause component wear, fatigue damage, accidents caused by component; Vibration damage component strength, so that the machine loose connections; vibration noise, detrimental to human health [1]. At present, in the foreign, the research on the vibration control technology of the machine tool is earlier, and the result is rich [2], Our study of machine vibration technology late, especially semi-active control technology is still in the experimental stage, there would be much room for improvement in the future. In the passive control technology, as early as mid-forty years, to improve at the basis of the German company Boehringer Ingelheim in Schlesinger studies [3], followed reinforced concrete as a machine bed and rails material, so that the machine has a good vibration performance, Mass production of a concrete lathe. In active control technology, Aggogeri et al based on piezoelectric actuators designed the machine control system active, the experimental results show that the surface finish of the workpiece in the active control systems for the process to be significantly higher than the finish is not applied when the active control, active control system to achieve good test results [4-7]. In the semi-active control technology, mao-hua wang of jilin agricultural university and yong-liang zhang of jilin university. Experiment analysis of Jun-yi Yu show that electro-rheological damper can select the size of the applied electric field in order to achieve control of vibration of milling machine tool holder system [8].

With the continuous development of high and new technology, new materials technology become one of the three pillars to promote social progress, so intelligent materials research is more popular with the people. MRF is a kind of new intelligent materials, use of smart materials-MRF semi-active control does not need external energy supply. According to the change of system input and requirements of the system output, real-time control system in some link stiffness, inertia and damping characteristics, so that the system can get the good vibration characteristic. It not only has 
active control the characteristics of strong adaptability, but also has the advantages of low energy consumption, high reliability, passive control wide attention by scholars and related research institutions at home and abroad, has good prospects for development.

In view of the rectangle parts of milling vibration, this paper developed milling vibration reduction devices based on MRF, In view of the rectangle parts of milling vibration, this paper developed a milling damping device based on MRF, and the milling system is the theoretical modeling and simulation analysis of dynamic characteristics, design the milling vibration fuzzy control system based on the magneto-rheological materials, and experiment to the milling chatter semi-active fuzzy control.

\section{Machine Tool Vibration Reduction System Based on Magneto-rheological Materials}

In the part milling, Toolholder is the place where the most prone to vibration, In order to improve the stability of the milling, design and manufacture of the vertical numerical control milling machine MR fluid vibration damping device structure and installation diagram as shown in Fig. 1. In this paper, the y direction is the vertical direction, and the magnetic fluid damping device is mainly used to control the vibration of the direction.

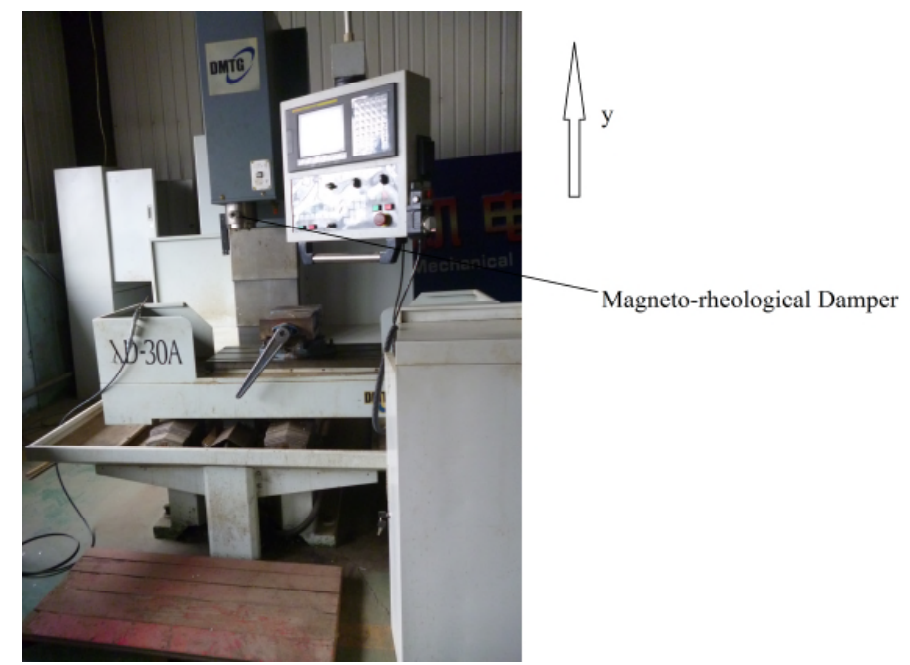

Fig. 1 Installation diagram of magnetic fluid damping device for machine tool.

The purpose on Machine tool vibration is makes the smallest vibration transfer to the end of the Machine tool, the vibration transfer characteristics is determined by the natural frequency of the excitation frequency components, systems, equivalent mass, and the damping coefficient of vibration damping device. This article only in the vertical direction vibration research of semi-active vibration isolation system dynamics modeling, and the damping ratio on the machine tool system are analyzed the influence of vibration transfer characteristics.

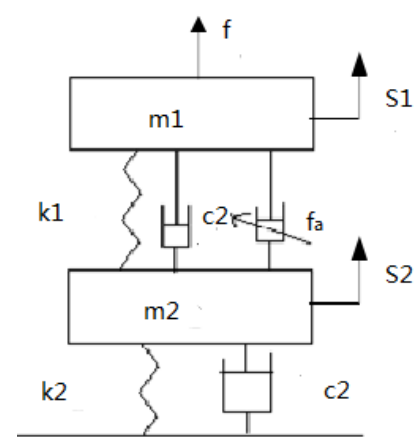

Fig. 2 Vibration reduction dynamics model of machine tool. 
The machine tool is simplified as a lumped mass $\mathrm{m}_{1}$, and the vibration damping device is simplified as a no mass spring $\mathrm{k}_{1}$ and damper $\mathrm{c}_{1}$, and the base is simplified as mass $\mathrm{m}_{2}$, equivalent stiffness $\mathrm{k}_{2}$ and equivalent damping $\mathrm{c}_{2}$ system. Among them:

$\mathrm{f}$ — the incentive of $\mathrm{m}_{1} ; \mathrm{f}_{\mathrm{a}}$ — controllable resistance; $\mathrm{s}_{1}$ —Displacement of machine tool;

$\mathrm{s}_{2}$ - The vibration displacement of equivalent quality - base.

From the kinetic model, the dynamic equation of the system is:

$$
\begin{aligned}
& \mathrm{m}_{1} \ddot{\mathrm{s}}_{1}+\mathrm{k}_{1}\left(\mathrm{~s}_{1}-\mathrm{s}_{2}\right)+\mathrm{c}_{1}\left(\dot{\mathrm{s}}_{1}-\dot{\mathrm{s}}_{2}\right)=\mathrm{f}+\mathrm{f}_{\mathrm{a}} \\
& \mathrm{m}_{2} \ddot{\mathrm{s}}_{2}+\mathrm{k}_{2} \mathrm{~s}_{2}+\mathrm{c}_{2} \dot{\mathrm{s}}_{2}=-\mathrm{f}_{\mathrm{a}}+\mathrm{k}_{1}\left(\mathrm{~s}_{1}-\mathrm{s}_{2}\right)+\mathrm{c}_{1}\left(\dot{\mathrm{s}}_{1}-\dot{\mathrm{s}}_{2}\right)
\end{aligned}
$$

The vibration reduction system of machine tool is analyzed, and calculate the transmission rate of vibration damping system by using impedance analysis method.

Displacement impedance $Z=F / X$, quality element displacement impedance $Z_{m}=-\omega^{2} \mathrm{~m}$, spring element displacement impedance $\mathrm{Z}_{\mathrm{k}}=\mathrm{k}$, the damping element displacement impedance $\mathrm{Z}_{\mathrm{c}}=\mathrm{j} \omega \mathrm{c}$. Therefore, the effective rate is:

$$
\begin{aligned}
& \mathrm{T}_{\mathrm{A}}=\mid\left\{\left[1-\left(\lambda^{2}+2 \xi_{1} \cdot 2 \xi_{2} \lambda\right)\left(\frac{\omega}{\omega_{\mathrm{n} 1}}\right)^{2}\right]^{2}+\left[\left(2 \xi_{1}+2 \xi_{2} \lambda\right) \frac{\omega}{\omega_{\mathrm{n} 1}}-2 \xi_{2} \lambda^{2}\left(\frac{\omega}{\omega_{\mathrm{n} 1}}\right)^{3}\right]^{2}\right\} /\{[1- \\
& \left.\left(1+\lambda^{2}+\mu \lambda^{2}+2 \xi_{1} \cdot 2 \xi_{2} \lambda\right)\left(\frac{\omega}{\omega_{\mathrm{n} 1}}\right)^{2}+\lambda^{2}\left(\frac{\omega}{\omega_{\mathrm{n} 1}}\right)^{4}\right]^{2}\left[\left[\left(2 \xi_{1}+2 \xi_{2} \lambda\right) \frac{\omega}{\omega_{\mathrm{n} 1}}-\left(2 \xi_{1} \lambda^{2}+2 \xi_{2} \lambda+\right.\right.\right. \\
& \left.\left.\left.\left.2 \xi_{1} \lambda^{2} \mu\right)\left(\frac{\omega}{\omega_{\mathrm{n} 1}}\right)^{3}\right]^{2}\right]\right\}\left.\right|^{0.5}
\end{aligned}
$$

Machine tools and the base of equivalent quality piece of the relative displacement between the transmission rate is:

$$
\begin{aligned}
& \mathrm{T}_{\mathrm{x}}=\left|\frac{\mathrm{S}_{1}-\mathrm{S}_{2}}{\mathrm{~F}}\right|=\mid \frac{1}{\mathrm{~m}_{1}}\left[\left(-\omega^{2}+\frac{\mathrm{k}_{2}}{\mathrm{~m}_{2}}\right)+\mathrm{j} \omega \frac{\mathrm{c}_{2}}{\mathrm{~m}_{2}}\right] /\left\{\left[\omega^{4}-\omega^{2}\left(\frac{\mathrm{m}_{1}}{\mathrm{~m}_{2}} \cdot \frac{\mathrm{k}_{1}}{\mathrm{~m}_{1}}+\frac{\mathrm{k}_{2}}{\mathrm{~m}_{2}}+\frac{\mathrm{k}_{1}}{\mathrm{~m}_{1}}+\frac{\mathrm{c}_{1}}{\mathrm{~m}_{1}} \cdot \frac{\mathrm{c}_{2}}{\mathrm{~m}_{2}}\right)+\frac{\mathrm{k}_{1}}{\mathrm{~m}_{1}} .\right.\right. \\
& \left.\left.\frac{\mathrm{k}_{2}}{\mathrm{~m}_{2}}\right]+\mathrm{j}\left[-\omega^{3}\left(\frac{\mathrm{m}_{1}}{\mathrm{~m}_{2}} \cdot \frac{\mathrm{c}_{1}}{\mathrm{~m}_{1}}+\frac{\mathrm{c}_{1}}{\mathrm{~m}_{1}}+\frac{\mathrm{c}_{2}}{\mathrm{~m}_{2}}\right)+\omega\left(\frac{\mathrm{k}_{1}}{\mathrm{~m}_{1}} \cdot \frac{\mathrm{c}_{2}}{\mathrm{~m}_{2}}+\frac{\mathrm{k}_{2}}{\mathrm{~m}_{2}} \cdot \frac{\mathrm{c}_{1}}{\mathrm{~m}_{1}}\right)\right]\right\} \mid
\end{aligned}
$$

Set $\omega_{\mathrm{n} 1}{ }^{2}=\frac{\mathrm{k}_{1}}{\mathrm{~m}_{1}}, \omega_{\mathrm{n} 2}{ }^{2}=\frac{\mathrm{k}_{2}}{\mathrm{~m}_{2}}, \mu=\frac{\mathrm{m}_{1}}{\mathrm{~m}_{2}}, \xi_{1}=\frac{\mathrm{c}_{1}}{2 \sqrt{\mathrm{m}_{1} \mathrm{k}_{1}}}, \xi_{2}=\frac{\mathrm{c}_{2}}{2 \sqrt{\mathrm{m}_{2} \mathrm{k}_{2}}}, \lambda=\frac{\omega_{\mathrm{n} 1}}{\omega_{\mathrm{n} 2}}$, into two type available: The relative transfer rate of the machine mass was normalized:

$$
\begin{aligned}
& \mathrm{T}_{\mathrm{X}}{ }^{\prime}=\mid\left[\left(-\frac{\omega^{2}}{\omega_{\mathrm{n} 1}} \lambda^{2}+\frac{1}{\omega_{\mathrm{n} 1}{ }^{2}}\right)^{2}+\left(2 \xi_{2} \lambda \frac{\omega}{\omega_{\mathrm{n} 1}{ }^{3}}\right)^{2}\right] /\left\{\left[1-\left(1+\lambda^{2}+\mu \lambda^{2}+2 \xi_{1} \cdot 2 \xi_{2} \lambda\right)\left(\frac{\omega}{\omega_{\mathrm{n} 1}}\right)^{2}+\right.\right. \\
& \left.\left.\lambda^{2}\left(\frac{\omega}{\omega_{\mathrm{n} 1}}\right)^{4}\right]^{2}+\left[\left(2 \xi_{1}+2 \xi_{2} \lambda\right) \frac{\omega}{\omega_{\mathrm{n} 1}}-\left(2 \xi_{1} \lambda^{2}+2 \xi_{2} \lambda+2 \xi_{1} \lambda^{2} \mu\right)\left(\frac{\omega}{\omega_{\mathrm{n} 1}}\right)^{3}\right]^{2}\right\}\left.\right|^{0.5}
\end{aligned}
$$

Research on the change of damping $\xi_{1}$ and damping $\xi_{2}$, and the influence of relative displacement transmissibility $\mathrm{T}_{\mathrm{X}}{ }^{\prime}$ and force transfer rate of $\mathrm{T}_{\mathrm{A}}$, the Fig. 3,4 is as follows:

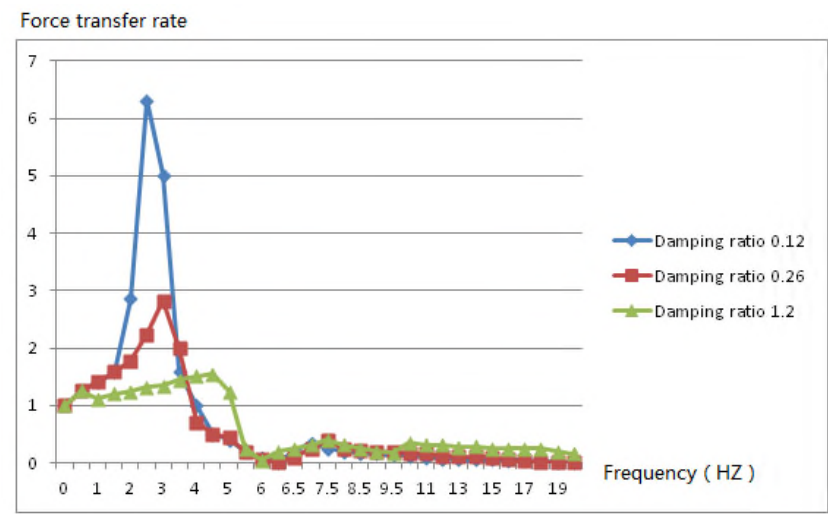

Fig. 3 Force transfer rate amplitude frequency response function. 


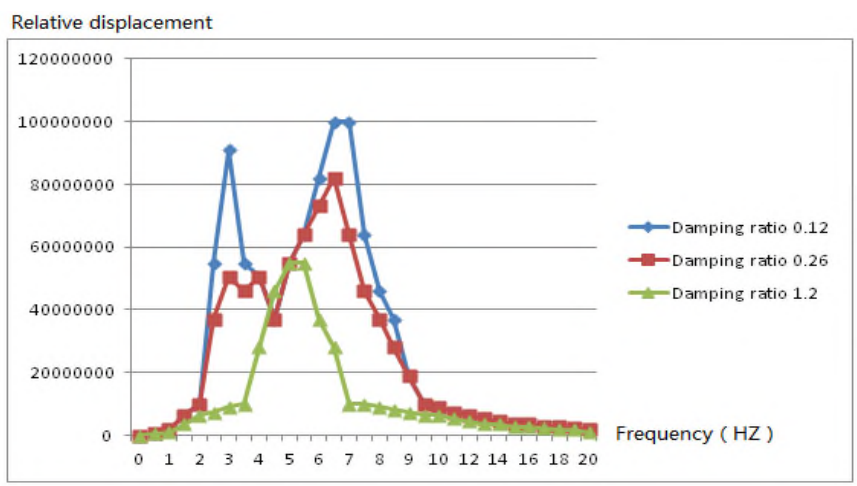

Fig. 4 Amplitude frequency response function of relative displacement transfer rate.

From the simulation result shows that different frequencies of vibration control to the demand of damping ratio, have certain contradiction, If in pursuit of wide range and the vibration isolation effect designed a small of the damping ratio of system, in many cases will lead to system instability. By above knowable, machine tool vibration reduction system of optimal damping ratio should be controlled at 0.26 . Therefore, through the magneto-rheological damper to the semi-active control of machine tool vibration system, taking a certain control algorithm, can adjust the damping ratio of the system, and real-time achieve well vibration damping effect.

\section{Design of Fuzzy Controller}

Highly nonlinear characteristics of magneto - rheological damper and vibration situation is more complex, So the fuzzy control algorithm is unnecessary to establish the accurate mathematical model of controlled objects; the system has strong robustness, Particularly suitable for Nonlinear and time-varying system control; Construction easy and simple control has been widely used in vibration control. Fuzzy Inference process for: (1) precise amount of blur; (2) Fuzzy Reasoning; (3) the ambiguity. The system structure as shown in Fig. 5.

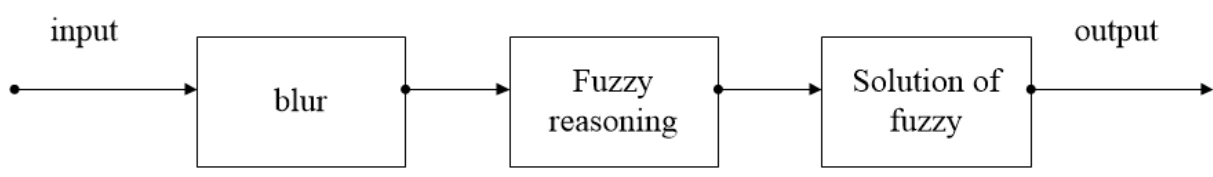

Fig. 5 Fuzzy system structure diagram.

For magneto-rheological Damping vibration of machine tool system, set up the of equivalent mass of vibration velocity $v_{2}(t)$ and Speed relative motion $\delta(t)$ between the tool and the base as the input of fuzzy control, Controllable equivalent damping ratio of $\xi_{\mathrm{a}}$ as the output of fuzzy controller.

Design of fuzzy controller are as follows [9]:

(1) Transformation of the domain

The input of the fuzzy set of fuzzy controller for: \{ negative, and in the negative, negative small, zero, are small, median, CP $\}$, Its range from the [ $-3,3]$. The output of the fuzzy set of fuzzy controller for: $\{$ zero, small, medium, large $\}$, its range from [ 0,3 ]. Transformation to perform on the field, got U, V, Y value.

(2) Fuzzy subset membership function

Gaussian membership function is used in this paper, the formula is:

$f(x, \sigma, c)=e^{-\frac{(s-c)^{2}}{2 \sigma^{2}}}$

The function curve is more gradual in the outlying areas, help to improve the stability of control.

(3) Fuzzy control rules

Fuzzy input value by fuzzy rules by fuzzy inference and fuzzy output value, General form of fuzzy rules: Rule $i$ : if $U$ is $A_{i}$ and $V$ is $B_{i}$ then $y$ is $D_{j}$. Among $A_{i}, B_{i}, D_{j}$ respectively for the input of fuzzy subsets and the output of fuzzy subsets. 
(4) Operational Rule of Fuzzy

For a given set of fuzzy rules, The total satisfaction of two input variables to a rule's premise condition is using the min operator, From input to output a subset of a subset of fuzzy implication and use the Min operator, The results of the rule of fuzzy clustering using the max operator.

Inputs and V two have been identified. Satisfied degree of the rule as follows:

$u R^{i}\left(U_{\circ}, V_{\circ} \circ\right)=u A^{i}(U \circ) \wedge u B^{i}(V)$

Among $\mathrm{uA}^{\mathrm{i}}(\mathrm{U})$ and $\mathrm{uB}^{\mathrm{i}}(\mathrm{V})$ represents a subset of the input quantities $\mathrm{x}$ and $\mathrm{v}$ on the input of membership.

And the rules for a subset of the output:

$\mathrm{uD}^{\mathrm{i}}(\mathrm{Y})=u \mathrm{R}^{\mathrm{i}}\left(\mathrm{U}_{\circ}, \mathrm{V}_{\circ}\right) \wedge \mathrm{uD} \mathrm{D}^{\mathrm{i}}(\mathrm{Y})$

Finally, the defuzzification method to Fuzzy Set the output to a single value $y_{0}$. In this paper, the application area of center of gravity method, the following formula:

$\mathrm{y}_{0}=\frac{\int \mathrm{u}_{\mathrm{D}} \mathrm{r}(\mathrm{y}) \mathrm{ydy}}{\int \mathrm{u}_{\mathrm{D}} \mathrm{r}(\mathrm{y}) \mathrm{dy}}$

The Test with Semi-active Fuzzy Control for Vibration of Machine Based on the Magneto-rheological Materials

Diagram of the test with Semi - Active fuzzy control for vibration of machine based on the magneto-rheological materials, as shown in Fig. 6.

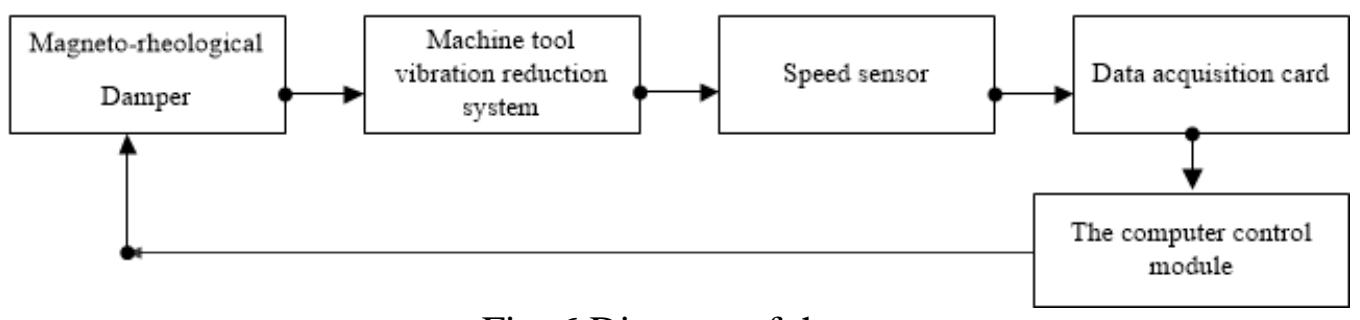

Fig. 6 Diagram of the test.

\section{Test Results}

The data, as shown in Fig. 7, is amplitude wave of damper without magnetic current. It was got at cutting conditions by processing in vertical directions, the spindle speed is $1500 \mathrm{r} / \mathrm{min}$, turning quantity is $1 \mathrm{~mm}$, and feed speed is $0.2 \mathrm{~mm} / \mathrm{r}$.

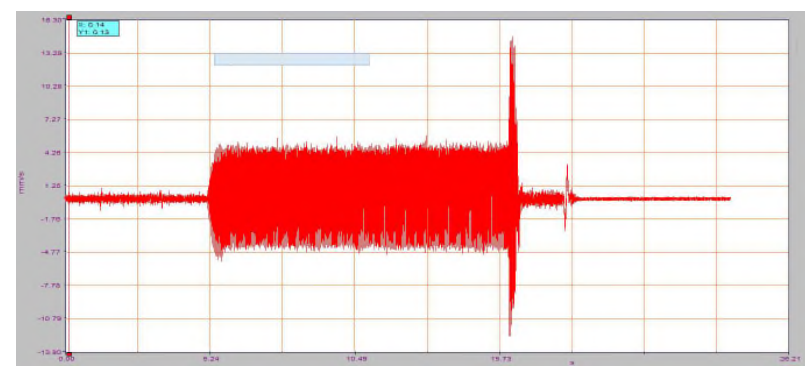

Fig. 7 Amplitude wave of damper without magnetic current.

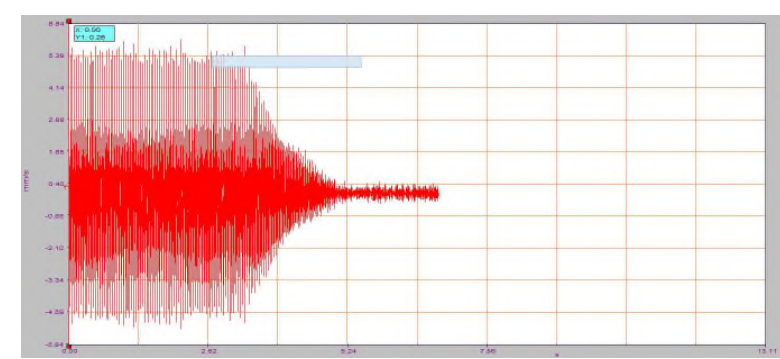

Fig. 8 Amplitude wave of damper with magnetic current

The data, as shown in Figure 8, is amplitude wave of damper with magnetic current. It was got at cutting conditions by the spindle speed is $1500 \mathrm{r} / \mathrm{min}$, turning quantity is $1 \mathrm{~mm}$, and feed speed is $0.5 \mathrm{~mm} / \mathrm{r}$. 
The experiments indicate that: the vibration of machine tool can be effectively suppressed when the system of machine based on the magneto-rheological materials combined with a damper with magnetic current.

\section{Conclusion}

For the problems occurred vibration in the rectangle parts milling, i developed milling device based on the magneto-rheological materials, it indicate that :we could get the best result by adjusting the damping ratio in real time. Therefore ,i design fuzzy control system of machine based on the magneto-rheological materials and doing experiments of test with Semi - Active fuzzy control for vibration of machine. The experiments indicate that: the fuzzy control system can effectively reduce the amplitude, restrain the milling vibration and ensure the progress of machining at cutting condition of the magneto-rheological damper.

\section{References}

[1] M. Z. Ren, Analysis and control and the calculation methods of mechanical vibration, Beijing: China Machine Press, 2011

[2] I.Zaghbani and V. Songmene, Estimation of machine-tool dynamic parameters during machining operation through operational modal analysis, Int. J. Mach. Tool. Manuf. 49(12) (2009) 947-957.

[3] S. Georg, Machine tool tests and alignment. Archive: P. I. Mech. Eng. 138 (1938) 59-119.

[4] F. Aggogeri, F. Al-Bender and B. Brunner, et al. Design of piezo-based AVC system for machine tool applications, Mech. Syst. Signal. Pr. 36(1) (2013) 53-65.

[5] J.Albizuri, M. H. Fernandes and I. Garitaonandia, et al. An active system of reduction of vibrations in a centerless grinding machine using piezoelectric actuators, Int. J. Mach. Tool. Manuf. 47 (2007) 1607-1614.

[6] M. Siddhpura and R. Paurobally, A review of chatter vibration research in turning. Int. J. Mach. Tool. Manuf. 61 (2012) 27-47.

[7] S. K. Choudhury, N. N. Goudimenko and V. A. Kudinov, On-line control of machine tool vibration in turning. Int. J. Mach. Tool. Manuf. 37(6) (1997) 801-811.

[8] M. H. Wang and L. Yong and J. Y. Yu. Experiment research of electro-rheological damper for milling machine vibration control, China Mech. Eng. 13(8) (2002) 650-651.

[9] Z. D. Xu and Y. Q. Guo, Neuro-fuzzy control strategy for earthquake-excited nonlinear magnetorlieological structures, Soil Dynam. Earthquake Eng. 28 (2008) 717-727. 